ISSN : 2580-2100 e-ISSN : 2580-6327

Tersedia daring http://horticulturae.ipb.ac.id
Comm. Horticulturae J, Februari 2018, 2(1):49-56 DOI : http://dx.doi.org/10.29244/chj.2.1.49-56

\title{
Varietas Cabai Hias AYESHA IPB
}

\author{
Ornamental chili AYESHA IPB variety
}

\begin{abstract}
Muhamad Syukur ${ }^{12^{*}}$, Sobir ${ }^{12}$, Awang Maharijaya ${ }^{12}$, Syarifah Iis Aisyah ${ }^{12}$, Dewi Sukma ${ }^{12}$, Sulassih ${ }^{1}$, Arya Widura Ritonga ${ }^{12}$, Muhammad Ridha Alfarabi Istiqlal ${ }^{12}$, Abdul Hakim ${ }^{12}$, Darda Efendi ${ }^{12}$, Ketty Suketi ${ }^{12}$, Undang $^{2}$, Tiara Yudilastari², Ratih Lestari², Devi Alvida ${ }^{2}$, Elsa Tirta Wulandari ${ }^{2}$ Bagas Akmala $^{2}$
\end{abstract}

${ }^{1}$ Pusat Kajian Hortikultura Tropika, LPPM IPB,

Jl. Raya Pajajaran Baranangsiang, Bogor, Indonesia

${ }^{2}$ Departemen Agronomi dan Hortikutura, Fakultas Pertanian IPB,

Jl. Meranti Kampus IPB Dramaga, Bogor 16680, Indonesia

Diterima 2 Januari 2018/Disetujui 30 Januari 2018

\begin{abstract}
Cabai (Capsicum annuum L.) have various in fruit shapes, fruit colors, fruit types, hot tasty and biochemical compound useful for fresh fruit, spicy and ornamental plant. Ornamental chili ideotype that are dwarf, high fruit set and various fruit colors. The aim this study to improve description characters in Ayesha IPB IPB variety, both qualitative and quantitative characters. The testers are 4 released varieties and 5 the other genotypes in randomized complete block design for 4 replication in green house at Leuwikopo field reserch in Darmaga, Bogor. Ayesha IPB IPB variety showed early flower in 13-16 days after planting, harvesting for commercial bucket in 65-70 days after planting, medium plant high that is 25.218 $\mathrm{cm}$, medium canopy width that is $46-53 \mathrm{~cm}$, good performance in canopy, round shape on fuit tip, various fuit colors that are yellow green for young fruit, orange for intermediate fuit and orange red for mature of fruit. Those description characters could be ornamental chili for Ayesha IPB, so it is important to protect the plant for ornamental plant commercialization.
\end{abstract}

Key word : color, fruit, orange, ornamental, red, round

\section{ABSTRAK}

Cabai (Capsicum annuum L.) memiliki keragaman dalam bentuk buah, warna buah, tipe buah, rasa dan kandungan biokimia, sehingga dapat bermanfaat untuk konsumsi segar, bumbu, tanaman hias dalam pot. Tanaman cabai hias memiliki idiotipe ukuran tanaman pendek, jumlah buah lebat, dan banyak warna pada buah dalam satu tanaman. Penelitian ini bertujuan untuk mendeskipsikan keunggulan karakter varietas Ayesha IPB IPB baik kuantitatif maupun kualitatif terhadap 4 varietas pembanding dan 5 genotipe lainnya yang berlokasi di rumah kaca kebun percobaan Leuwikopo Darmaga Kabupaten Bogor, dengan menggunakan rancangan kelompok lengkap teracak sebanyak 4 ulangan. Varietas Ayesha IPB memiliki keunggulan umur berbunga pertama cepat (13-16 HST) dan umur komersialisasi berupa tanaman di dalam pot mulai 65-70 HST, bentuk tanaman ideal dengan tinggi tanaman $25.218 \mathrm{~cm}$, lebar tajuk $46-53 \mathrm{~cm}$ dan bentuk tajuk kompak, serta keunikan organ pada bentuk ujung buah tumpul dan membulat (obtuse), ada beberapa warna buah dalam satu tanaman, warna buah muda kuning (yellow green group 145-C), warna buah intermediet oranye (orange group N25-B), warna buah matang oranye tua kemerahan (orange red N30-B) dan cocok untuk tanaman hias, sehingga perlu perlindungan varietas sebagai komoditas komersial.

Kata kunci : buah, bulat, hias, merah, oranye, warna

\section{PENDAHULUAN}

Cabai (Capsicum annuum L.) memiliki keragaman dalam bentuk buah, warna buah, tipe buah, rasa dan kandungan biokimia (Sokona D et al., 2013) sehingga

\footnotetext{
* Penulis untuk korespondensi. e-mail: muhsyukur@ipb.ac.id
}

potensial dan bermanfaat sebagai bahan pangan, nutrisi, obat-obatan, kosmetik, dan pendapatan. Cabai mengandung vitamin A, C, K, B6, kalsium, zat besi, seng, serat dan capsaicin. Capsaicin (C18H27NO3) termasuk ke dalam golongan alkaloid dan hanya ditemukan pada cabai sebagai rasa pedas bermanfaat sebagai anti kanker dan anti oksidan (Sokona D et al., 2013). Cabai hias bermanfaat untuk konsumsi segar, bumbu, tanaman hias dalam pot dan tanaman untuk taman (Esin et al., 2016). Tanaman cabai 
hias berpotensi untuk dikomersialisasikan dengan harga yang lebih tinggi karena perbanyakan memiliki variasi warna bunga dan buah (Esin et al., 2016). Pertumbuhan tanaman cepat, tanaman berukuran pendek dan memiliki nilai estetika (Rego et al., 2012).

Cabai hias belum banyak dikembangkan di Indonesia, tetapi minat konsumen cukup besar. Tanaman cabai hias varietas Ayesha IPB di IPB saat ini masih diusahakan untuk kelas benih penjenis (breeder seed), sehingga ketersediaan benih masih terbatas. Kelas benih sebar belum optimal dikembangkan. Idiotipe yang diharapkan dari hasil persilangan adalah untuk mendapatkan (1) ukuran tanaman pendek, (2) buah membulat, (3) buah memanjang, (4) ada pemendekan ruas, (5) jumlah buah lebat, dan (6) buah banyak warna dalam satu tanaman.

Pusat Kajian Hortikultura Tropika (PKHT) LPPM IPB dan Departemen Agronomi dan Hortikultura (AGH) Fakultas Pertanian IPB memiliki galur cabai hias hasil persilangan tetua betina IPB C318 (selfing Explosive Embeer), merupakan donor warna buah ungu dan kelebatan buah. Tetua jantan adalah cabai hias IPB C320 (selfing dari Numex Twilight), merupakan donor buah membulat dan ukuran pendek (dwarf). NuMex Twi-light tergolong tanaman yang tahan salinitas tinggi (Niu G et al., 2012). Hasil persilangan tersebut menghasilkan calon varietas baru yaitu Ayesha IPB. Cabai hias varietas Ayesha IPB merupakan salah calon varietas baru yang berpotensi untuk dikembangkan sebagai tanaman hias. Idiotipe ukuran tanaman pendek, buah membulat, jumlah buah lebat, bentuk tajuk kompak dan banyak warna pada buah dalam satu tanaman. Penampilan banyak warna pada cabai genotipe Ayesha IPB dapat menarik penikmat tanaman hias. Cabai hias varietas Ayesha IPB diminati konsumen karena memiliki bentuk buah yang unik, buah berwarna orange kemerahan dan lebat. Tanaman cabai hias varietas Ayesha IPB di IPB, hingga saat ini belum tercatat secara rinci sebagai varietas, sehingga diharapkan deskripsi varietas dapat dilanjutkan pada tahap pendaftaran varietas secara komersial.

\section{SILSILAH VARIETAS}

Perakitan varietas cabai hias (Capsicum annuum L.) AYESHA IPB IPB diarahkan kepada peningkatan arsitektur tanaman dan keindahan buah. Varietas AYESHA IPB IPB adalah varietas bersari bebas. Tetua betina yang digunakan adalah cabai hias IPB C318 (selfing Explosive Embeer), merupakan donor warna buah ungu dan kelebatan buah. Tetua jantan adalah cabai hias IPB C320 (selfing dari Numex Twilight), merupakan donor buah membulat dan ukuran pendek ( $d$ warf). Persilangan keduanya diharapkan menghasilkan cabai hias ukuran tanaman dwarf, buah membulat, jumlah buah lebat dan banyak warna dalam satu tanaman.

Cabai adalah termasuk tanaman menyerbuk sendiri yang diperbanyak melalui benih, namun demikian persentase menyerbuk silang cukup tinggi yaitu dapat mencapai 35\%. Oleh karena itu varietas cabai yang dihasilkan dapat berupa cabai hibrida maupun bersari bebas, sehingga perakitan varietas cabai dapat mengikuti alur perakitan varietas hibrida untuk menghasilkan varietas hibrida dan alur perakitan varietas galur murni (dimodifikasi) untuk menghasilkan varietas bersari bebas.

Berdasarkan tipe perkembangbiakan tanaman tersebut maka metode pemuliaan tanaman cabai diantaranya adalah Bulk, Pedigree, SSD, Silang Balik, Seleksi Massa, dan Seleksi Galur Murni. Perakitan varietas AYESHA IPB IPB menggunakan Metode Pemuliaan Pedigree. Persilangan antara IPB C318 x IPB C320 menghasilkan F1. Benih F1 diselfing menghasilkan F2. Benih F2 ditanam dan diseleksi menghasilkan benih F3.318320-1. Benih F3 tersebut ditanam dan diseleksi menghasilkan F4.318320-1-3U. Benih F4 tersebut ditanam dan diseleksi menghasilkan F5.318320-1-3U-1. Benih F5 tersebut ditanam dan diseleksi menghasilkan F6.318320-1-3U-1-1. Galur ini bersama-sama dengan galur-galur hasil persilangan lainnya dilakukan uji daya hasil pendahuluan untuk uji multilokasi dalam rangka pelepasan varietas tanaman (Gambar 1). IPB.318320-1-3U1-1 diberi nama AYESHA IPB IPB.

\section{BAHAN DAN METODE}

Penelitian dilakukan sejak Januari sampai dengan Juli 2016. Berlokasi di rumah kaca Kebun Percobaan Leuwikopo, Darmaga, Bogor, Jawa Barat. Kebun Percobaan Leuwikopo berada pada ketinggian 200-250 mdpl, curah hujan 3.500$4.000 \mathrm{~mm}$ per tahun dan suhu berkisar $25-30{ }^{\circ} \mathrm{C}$.

Bahan tanaman yang digunakan adalah populasi varietas cabai hias Ayesha IPB hasil seleksi pedigree dari

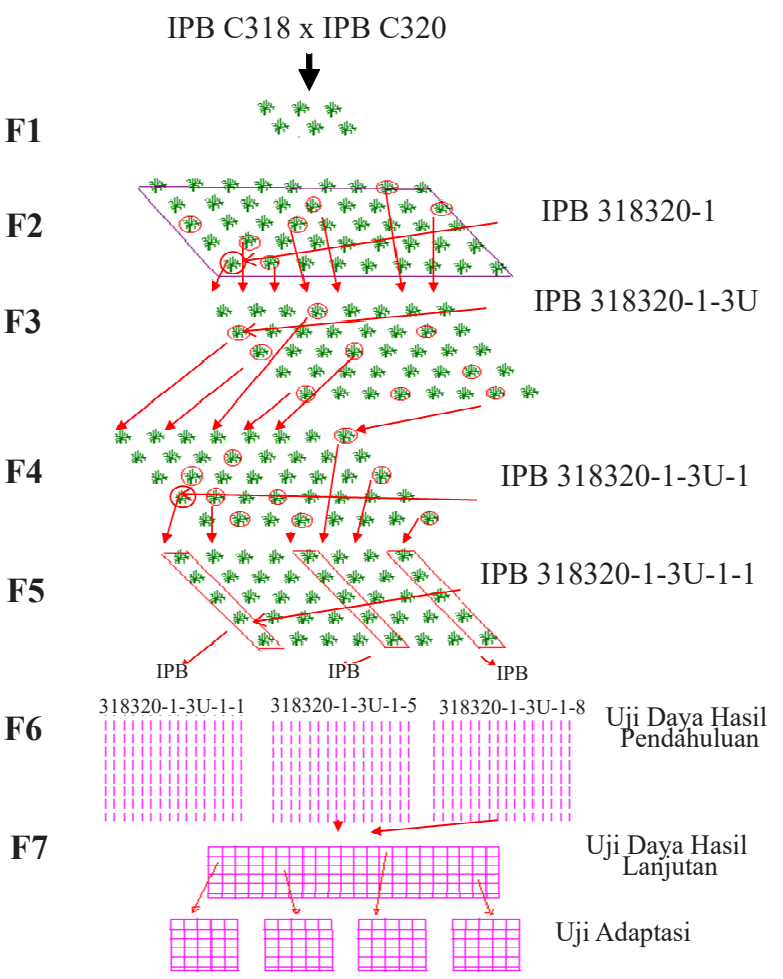

Gambar 1. Metode Pemuliaan Pedigree untuk Perakitan Varietas Cabai AYESHA IPB 
persilangan IPB C318 x IPB C320 dengan genotipe lainnya yaitu G1U, G4K, G5K1, G5K2, G120, G311K dan tiga varietas pembanding yang sudah dilepas varietas yaitu Seroja, Ungara, dan Bara. Karakter Pengamatan karakter kualitatif mengacu pada Naktuinbouw (2010), IPGRI (1995) dan Buku Panduan Pengujian Individual (PPI) untuk pedoman pelaksanaan pengujian Kebaruan, Keunikan, Keseragaman dan Kestabilan (BUSS) spesies Cabai (2006). Alat yang digunakan antara lain jangka sorong, color chart Royal Horticulture Studies sixth edition dan timbangan analitik. Rancangan percobaan yang digunakan dalam penelitian ini adalah Rancangan Kelompok Lengkap Teracak (RKLT) satu faktor yaitu varietas dengan 4 ulangan di dalam rumah kaca. Analisis dilakukan dengan menggunakan SAS, jika nilai F-hitung berbeda nyata pada taraf 5\% maka dilanjutkan dengan uji DMRT.

Persemaian benih dilakukan dengan menggunakan tray semai yang diisi menggunakan media tanam komersial. Pemupukan dilakukan jika tanaman yang telah mempunyai 2 daun dengan menggunakan pupuk AB Mix dengan dosis $5 \mathrm{ml}^{-1}$ yang diaplikasikan seminggu sekali. Penanaman dilakukan dengan memindahkan bibit cabai berumur sekitar 5 minggu ke dalam pot yang telah berisi media tanam. Pemupukan dilakukan setiap seminggu sekali dengan pupuk AB Mix dengan dosis $5 \mathrm{ml}^{-1}$. Pengendalian hama dilakukan dua kali dalam seminggu kali dengan dengan menggunakan fungisida berbahan aktif propineb. Kegiatan pemanenan ditujukan pada kondisi tanaman sudah memiliki buah masak pertama kali sebagai tanaman hias di dalam pot.

Pengamatan karakter kualitatif dan kuantitatif dengan mengacu pada Pedoman Descriptors for Capsicum (Capsicum spp.) oleh Naktuinbouw Calibration Book Capsicum annuum L. tahun 2010 dan IPGRI (International Plant Genetic Resources Institute) tahun 1995. Pengamatan dilakukan pada seluruh populasi tanaman cabai yang ditanam. Karakter kualitatif yang diamati adalah : warna batang, rambut pada node batang, habitus, pemendekan ruas, bentuk daun, tepi daun, bentuk tepi daun, ujung daun, warna daun, warna mahkota bunga, warna kelopak bunga, warna tangkai bunga, posisi bunga, bentuk buah, bentuk pangkal buah, bentuk ujung buah, lekuk buah, antosianin buah, warna buah muda, warna buah intermediate, warna buah matan. Karakter kuantitatif yang diamati adalah : tinggi tanaman $(\mathrm{cm})$, tinggi dikotomus $(\mathrm{cm})$, diameter batang $(\mathrm{mm})$, panjang daun $(\mathrm{cm})$, lebar daun $(\mathrm{cm})$, umur berbunga (HST), umur panen (HST), panjang tangkai buah $(\mathrm{cm})$, panjang buah $(\mathrm{cm})$, diameter buah $(\mathrm{cm})$, bobot per buah $(\mathrm{g})$, tebal daging buah $(\mathrm{mm})$, bobot buah per tanaman (g), dan jumlah buah per tanaman.

\section{HASIL DAN PEMBAHASAN}

\section{Karakter Kualitatif}

Karakter kualitatif varietas Ayesha IPB memiliki batang berwarna hijau (Green 143-C), berbeda dengan genotipe G311K, G1U dan Ungara berwarna batang ungu (Purple N79-A), sedangkan genotipe G120, Seroja dan Bara berwarna hijau keunguan. Varietas Ayesha IPB memiliki rambut pada node batang medium, sedangkan genotipe G4K dan Seroja memiliki jumlah rambut yang banyak. Kandungan antosianin medium pada varietas Ayesha IPB, sedangkan genotipe G120, G311K, G1U dan varietas Ungara yang memiliki kandungan antosianin yang tinggi (banyak) pada node batangnya. Varietas Ayesha IPB memiliki habitus tanaman kompak. Varietas Ayesha IPB tidak memikili pemendekan ruas. Varietas Ayesha IPB memiliki bentuk daun lanset dan tepi daun rata Warna daun varietas Ayesha IPB berwarna hijau (Green 137-C), berbeda dengan warna daun varietas pembanding Ungara yang memiliki warna daun hijau keunguan (Green NN137-A) serta pembanding Bara berwarna hijau tua (Green NN137-A). Karakter kualitatif ujung daun untuk varietas Ayesha IPB berbentuk meruncing, mirip dengan seluruh genotipe dan varietas pembanding.

Varietas Ayesha IPB memiliki tangkai bunga dan kelopak berwarna hijau seperti sedangkan Ungara, G311K dan G1U berwarna ungu. Karakter bentuk buah varietas Ayesha IPB, Seroja, Ungara dan G311K adalah triangular dengan pangkal buah yang rompang.Karakter warna buah varietas Ayesha IPB, G4K, G5K2, dan G5K1 memiliki buah muda, intermediat dan tua adalah berwarna kuning kehijauan (Yelow green group 145-C), orange (Orange N25-B) dan orange tua kemerahan (Orange red N30-B). Berbeda dengan varietas pembanding Bara yang memiliki buah berwarna hijau (Green 141-B), orange tua dan merah, sedangkan genotipe G120, G311K, G1U, G5K1 serta varietas Ungara yang memiliki buah berwarna ungu (Violet blue group N92-A), orange tua, dan merah. Varietas Ayesha IPB dan Bara memiliki lekuk keriting buah yang medium, sedangkan genotipe G5K1 memiliki sedikit lekuk keriting, serta varietas Seroja, Ungara dan genotipe G311K memiliki buah yang rata. Varietas Ayesha IPB, Bara, G4K, G3U, dan G5K2, tidak memiliki antosianin pada buah muda, sedangkan pada genotipe G5K1 terdapat sedikit antosianin. Berbeda dengan genotipe G120, G311K dan varietas Ungara yang memiliki antosianin yang menyeluruh pada buah mudanya.

\section{Karakter Kuantitatif}

Species Capsicum annuum terbagi menjadi 5 sub species yaitu Capsicum annum var. abbreviatum, Capsicum annuum var. annum, Capsicum annum var. accuminatum, Capsicumannum var grossum, dan Capsicumannum var. glabriusculum (Zhigila et al., 2014). Varietas cabai hias Ayesha IPB termasuk Capsicum annuum var. annum. Pengembangan pemuliaan tanaman cabai hias ditujukan untuk karakter tanaman yang pendek, habitus intermediate, 3-5 kali panen, cepat berbunga, warna buah, ukuran buah dan bentuk buah (Silva et al, 2015). Hasil rekapitulasi sidik ragam menunjukkan bahwa varietas yang diuji berpengaruh sangat nyata pada karakter tinggi tanaman, dikotomus, diameter batang, panjang daun, lebar daun, panjang tangkai buah, panjang buah, diameter buah, bobot buah, tebal daging buah, umur panen, umur berbunga, bobot pertanaman, jumlah buah pertanaman (Tabel 1). 
Genus Capsicum memiliki keragaman baik di dalam species maupun antar species pada tipe buah, warna buah, rasa dan kandungan biokimia. Berdasarkan hasil analisis varietas Ayesha IPB $(25.218 \mathrm{~cm})$ dikelompokan sebagai tanaman hias yang memiliki tinggi tanaman berukuran sedang dibandingkan dengan tanaman pembanding (Bara, Seroja, dan Ungara), sedangkan G311K sangat pendek (Tabel 2). Karakter tinggi dikotomus varietas Ayesha IPB berukuran sedang $(9.390 \mathrm{~cm})$, sedangkan varietas pembanding Bara $(24.718 \mathrm{~cm})$ dan Ungara $(16.648 \mathrm{~cm})$. Diameter batang varietas Ayesha IPB berukuran sedang $(4.6950 \mathrm{~cm})$ dibandingkan dengan varietas Bara yang memiliki batang terbesar $(6.8625 \mathrm{~cm})$, varietas Ungara berbatang besar $(5.3000 \mathrm{~cm})$ dan G4K berbatang kecil $(3.9625 \mathrm{~cm})$ (Tabel 2).

Varietas Ayesha IPB memiliki panjang daun sedang $(4.3625 \mathrm{~cm})$, dibandingkan dengan varietas pembanding Bara $(7.8975 \mathrm{~cm})$ dan genotipe G4K $(3.2175 \mathrm{~cm})$. Karakter lebar daun varietas Ayesha IPB termasuk sedang (1.8975 $\mathrm{cm})$, apabila dibandingkan dengan varietas pembanding Bara $(3.6875 \mathrm{~cm})$ dan genotipe G311K $(1.3150 \mathrm{~cm})$. Umur berbunga varietas Ayesha IPB tergolong cepat (15 HST) dibandingkan dengan Bara (27 HST) dan Ungara (26 HST). (Tabel 2). Umur panen tercepat pada varietas Seroja (61.918 HST), sedangkan varietas Ayesha IPB sedang (69.250 HST) dan genotipe G311K sangat lambat yaitu 80 HST. Varietas Ayesha IPB memiliki umur panen sedang (69.250 HST) dan genotipe G311K sangat lambat yaitu 80 HST (Tabel 2).

Varietas Ayesha IPB memiliki tangkai buah yang pendek $(1.7200 \mathrm{~cm})$, dibandingkan dengan varietas Bara $(3.5475 \mathrm{~cm})$. Ukuran buah varietas Ayesha IPB tergolong pendek $(2.3025 \mathrm{~cm})$, dibandingkan dengan genotipe $\mathrm{G} 311 \mathrm{~K}$ sangat pendek $(1.8375 \mathrm{~cm})$ dan terpanjang adalah genotipe

Tabel 1. Rekapitulasi signifikansi karakter kuantitatif pada cabai hias Ayesha IIPB

\begin{tabular}{rlcc}
\hline No. & \multicolumn{1}{c}{ Karakter } & Signifikansi & KK $(\%)$ \\
\hline 1 & Tinggi tanaman & $* *$ & 21.11 \\
2 & Tinggi dikotomus & $* *$ & 16.93 \\
3 & Diameter batang & $* *$ & 14.87 \\
4 & Panjang daun & $* *$ & 18.47 \\
5 & Lebar daun & $* *$ & 19.09 \\
6 & Panjang Tangkai Buah & $* *$ & 7.97 \\
7 & Panjang Buah & $* *$ & 10.65 \\
8 & Diameter buah & $* *$ & 15.37 \\
9 & Bobot buah & $* *$ & 17.39 \\
10 & Tebal daging buah & $* *$ & 17.7 \\
11 & Umur panen & $* *$ & 5.31 \\
12 & Umur berbunga & $* *$ & 58.4 \\
13 & Bobot buah pertanaman & $* *$ & 57.8 \\
14 & Jumlah buah pertanaman & & 15.78 \\
\hline
\end{tabular}

Keterangan : $\mathrm{KK}=$ koefisien keragaman, $* *$ sangat berbeda nyata pada taraf $5 \%$
G5K2 (4.0350 cm) (Tabel 3). Berdasarkan hasil analisis (Tabel 3) karakter diameter buah varietas Ayesha IPB berukuran sedang $(10.3850 \mathrm{~cm})$ dan varietas Ungara yaitu sebesar $13.8800 \mathrm{~cm}$, sedangkan genotipe G4K berukuran kecil $(5.1700 \mathrm{~cm})$. Karakter bobot buah varietas Ayesha IPB berukuran kecil (1.0800 g), apabila dibandingkan dengan varietas pembanding varietas Ungara (2.3350 g) dan genotipe G1U memiliki bobot sangat kecil (0.5975 g).

Varietas Ayesha IPB memiliki tebal daging buah berukuran sedang $(1.0525 \mathrm{~mm})$, sedangkan varietas Ungara berdaging buah tebal $(1.6400 \mathrm{~mm})$ dan genotipe G1U tipis $(0.5975 \mathrm{~mm})$. Varietas Ayesha IPB memiliki bobot buah per tanaman sedang (52.37 g), dengan pembanding varietas Bara (183.74 g) dan G311K (25.46 g). Varietas Ayesha IPB memiliki jumlah buah sedang (73.22 buah) sedangkan varietas Seroja memiliki sedikit (37.37 buah) dan Bara menunjukan tertinggi yaitu 254.85 buah (Tabel 3 ).

\section{Unsur Kebaruan dan Keunggulan Calon Varietas}

Penetapan keunggulan varietas dapat dilakukan melalui pendekatan uji observasi. Uji observasi dilakukan terhadap tanaman tahunan atau tanaman semusim yang diproduksi secara terbatas, dan respon genetik sangat spesifik terhadap lingkungan tumbuh. Keunggulan varietas dapat dinyatakan dalam standar karakter sebagai berikut : (1) daya hasil tinggi, (2) ketahanan terhadap organisme pengganggu tumbuhan, (3) ketahanan terhadap cekaman lingkungan, (4) umur dan musim panen yang spesifik, (5) mutu hasil, (6) ketahanan simpan, (7) toleran terhadap kerusakan mekanis, (8) bentuk tanaman ideal, (9) keunikan organ vegetatif dan atau generatif, (10) mempunyai nilai pasar yang spesifik dan (11) khusus untuk batang bawah, dinyatakan dalam bentuk ketahanan terhadap penyakit tular tanah dan atau terhadap cekaman lingkungan serta tingkat kompatibilitas dengan beberapa varietas batang atas yang dinyatakan unggul (Deptan, 2011).

Capsicum memiliki keragaman baik di dalam species maupun antar species pada tipe buah, warna buah, rasa dan kandungan biokimia. Keragaman dapat terbentuk karena viabilitas pollen $C$. annuum var. annuum sangat tinggi mencapai 90.8\% (Monteiro et al., 2011). Keragaman pada varietas cabe terdapat pada bentuk dan ukuran buah (Zhigila et al., 2014). Varietas cabai hias Ayesha IPB berpotensi untuk dikembangkan sebagai varietas baru karena memiliki keunggulan pada umur dan musim panen yang spesifik, bentuk tanaman ideal dan keunikan organ vegetatif dan generatif (Tabel 4).

\section{Deskripsi Varietas}

Varietas Ayesha IPB mendapatkan tanda daftar di Kementerian Pertanian sejak tahun 2016 berdasarkan Sertifikat tanda daftar PPVTPP Kementan No : 430/ PVHP/2016. Karakter unggul warna buah dalam satu tanaman varietas Ayesha merupakan daya tarik sendiri yaitu warna buah. Deskripsi varietas Ayesha IPB terdapat pada Tabel 4 dan Gambar 2. 
Tabel 2. Keragaan karakter kuantitatif varietas Ayesha dengan tanaman pembanding varietas Ayesha dengan tanaman pembanding

\begin{tabular}{lccccccc}
\hline \multicolumn{1}{c}{ Genotipe } & TT & TD & DB & PD & LD & UB & UP \\
\hline Bara & $67.600^{\mathrm{a}}$ & $24.718^{\mathrm{a}}$ & $6.8625^{\mathrm{a}}$ & $7.8975^{\mathrm{a}}$ & $3.6875^{\mathrm{a}}$ & $27.500^{\mathrm{a}}$ & $69.250^{\mathrm{bc}}$ \\
Ungara & $39.643^{\mathrm{b}}$ & $16.648^{\mathrm{b}}$ & $5.3000^{\mathrm{b}}$ & $7.2425^{\mathrm{ab}}$ & $2.9700^{\mathrm{b}}$ & $26.333^{\mathrm{a}}$ & $69.250^{\mathrm{b}}$ \\
Seroja & $31.993^{\mathrm{bc}}$ & $12.425^{\mathrm{c}}$ & $4.9550^{\mathrm{bc}}$ & $6.0600^{\mathrm{bc}}$ & $2.8575^{\mathrm{bc}}$ & $16.750^{\mathrm{bc}}$ & $61.918^{\mathrm{c}}$ \\
Ayesha & $25.218^{\mathrm{c}}$ & $9.390^{\mathrm{cd}}$ & $4.6950^{\mathrm{bc}}$ & $4.3625^{\text {de }}$ & $1.8975^{\text {def }}$ & $15.500^{\mathrm{bc}}$ & $65.000^{\mathrm{c}}$ \\
G1U & $27.658^{\mathrm{c}}$ & $12.568^{\mathrm{c}}$ & $4.4700^{\mathrm{bc}}$ & $3.9475^{\text {de }}$ & $1.6575^{\text {def }}$ & $13.833^{\mathrm{c}}$ & $69.250^{\mathrm{b}}$ \\
G5K2 & $24.858^{\mathrm{c}}$ & $8.700^{\mathrm{d}}$ & $4.4700^{\mathrm{bc}}$ & $5.1875^{\mathrm{cd}}$ & $2.0150^{\mathrm{de}}$ & $16.500^{\mathrm{bc}}$ & $65.000^{\mathrm{bc}}$ \\
G5K1 & $24.625^{\mathrm{c}}$ & $10.233^{\mathrm{cd}}$ & $4.0950^{\mathrm{c}}$ & $5.2700^{\mathrm{cd}}$ & $2.2650^{\mathrm{cd}}$ & $18.918^{\mathrm{b}}$ & $65.000^{\mathrm{bc}}$ \\
G120 & $23.583^{\mathrm{c}}$ & $10.200^{\mathrm{cd}}$ & $4.5500^{\mathrm{bc}}$ & $3.6075^{\mathrm{e}}$ & $1.5100^{\text {ef }}$ & $13.418^{\mathrm{c}}$ & $65.000^{\mathrm{bc}}$ \\
G4K & $21.993^{\mathrm{c}}$ & $8.200^{\mathrm{d}}$ & $3.9625^{\mathrm{c}}$ & $3.2175^{\mathrm{e}}$ & $1.4325^{\mathrm{ef}}$ & $14.918^{\mathrm{bc}}$ & $65.000^{\mathrm{c}}$ \\
G311K & $11.658^{\mathrm{d}}$ & $4.625^{\mathrm{e}}$ & $3.9750^{\mathrm{c}}$ & $3.3250^{\mathrm{e}}$ & $1.3150^{\mathrm{f}}$ & $23.750^{\mathrm{a}}$ & $80.000^{\mathrm{a}}$ \\
\hline
\end{tabular}

Keterangan: $\quad \mathrm{TT}=$ tinggi tanaman, $\mathrm{TD}=$ tinggi dikotomus, $\mathrm{DB}=$ diameter batang, $\mathrm{PD}=$ panjang daun, $\mathrm{LD}=$ lebar daun, $\mathrm{UB}=$ umur berbunga, UP = umur panen. Angka-angka yang diikuti dengan huruf yang sama pada kolom yang sama tidak berbeda nyata pada DMRT taraf $5 \%$

Tabel 3. Keragaan karakter kuantitatif varietas Ayesha dengan tanaman pembanding varietas Ayesha dengan tanaman pembanding

\begin{tabular}{|c|c|c|c|c|c|c|c|}
\hline Genotipe & PTB & PB & DB & BB & TDB & BBT & JBP \\
\hline Bara & $3.5475^{\mathrm{a}}$ & $3.6350^{\mathrm{a}}$ & $7.0575^{\mathrm{c}}$ & $1.0150^{c}$ & $0.6825^{\mathrm{cd}}$ & $183.74^{\mathrm{a}}$ & $254.85^{\mathrm{a}}$ \\
\hline Ungara & $2.4250^{\mathrm{bc}}$ & $2.4925^{b c}$ & $13.8800^{\mathrm{a}}$ & $2.3350^{\mathrm{a}}$ & $1.6400^{\mathrm{a}}$ & $60.65^{\mathrm{b}}$ & $44.82^{b}$ \\
\hline Seroja & $2.5625^{\mathrm{b}}$ & $2.8025^{\mathrm{b}}$ & $9.3550^{\mathrm{b}}$ & $1.1725^{\mathrm{bc}}$ & $0.9100^{\mathrm{bc}}$ & $43.94^{b}$ & $37.37^{b}$ \\
\hline Ayesha & $1.7200^{\mathrm{d}}$ & $2.3025^{\mathrm{c}}$ & $5.7575^{\mathrm{c}}$ & $0.5975^{\mathrm{d}}$ & $0.5975^{\mathrm{d}}$ & $52.37^{\mathrm{b}}$ & $73.22^{\mathrm{b}}$ \\
\hline G1U & $1.7200^{\mathrm{d}}$ & $2.6525^{b c}$ & $10.3850^{\mathrm{b}}$ & $1.0800^{c}$ & $1.0525^{\mathrm{b}}$ & $47.30^{\mathrm{b}}$ & $93.12^{\mathrm{b}}$ \\
\hline G5K2 & $2.4200^{\mathrm{bc}}$ & $4.0350^{\mathrm{a}}$ & $5.6400^{c}$ & $1.2525^{\mathrm{bc}}$ & $0.8300^{\mathrm{bcd}}$ & $25.86^{\mathrm{b}}$ & $26.42^{\mathrm{b}}$ \\
\hline G5K1 & $2.3575^{\mathrm{bc}}$ & $4.0300^{\mathrm{a}}$ & $6.8300^{c}$ & $1.4150^{\mathrm{b}}$ & $1.0575^{\mathrm{b}}$ & $70.88^{b}$ & $78.63^{b}$ \\
\hline G120 & $1.6875^{\mathrm{d}}$ & $2.4975^{\mathrm{bc}}$ & $6.7325^{\mathrm{c}}$ & $0.6700^{\mathrm{d}}$ & $0.7225^{\mathrm{cd}}$ & $43.10^{\mathrm{b}}$ & $73.22^{\mathrm{b}}$ \\
\hline G4K & $2.1950^{c}$ & $2.4150^{\mathrm{bc}}$ & $5.1700^{c}$ & $0.4950^{\mathrm{d}}$ & $0.8150^{\mathrm{bc}}$ & $43.10^{\mathrm{b}}$ & $90.67^{b}$ \\
\hline $\mathrm{G} 311 \mathrm{~K}$ & $1.5100^{\mathrm{d}}$ & $1.8375^{\mathrm{d}}$ & $6.2025^{\mathrm{c}}$ & $0.4500^{\mathrm{d}}$ & $0.8275^{\text {bcd }}$ & $25.46^{\mathrm{b}}$ & $78.73^{\mathrm{b}}$ \\
\hline
\end{tabular}

Keterangan: $\mathrm{PTB}=$ panjang tangkai buah, $\mathrm{PB}=$ panjang buah, $\mathrm{DB}=$ diameter buah, $\mathrm{BB}=$ bobot buah, TDB = tebal daging buah, $\mathrm{BBT}=$ bobot buah per tanaman, JBP = jumlah buah per tanaman. Angka-angka yang diikuti dengan huruf yang sama pada kolom yang sama tidak berbeda nyata pada DMRT taraf $5 \%$

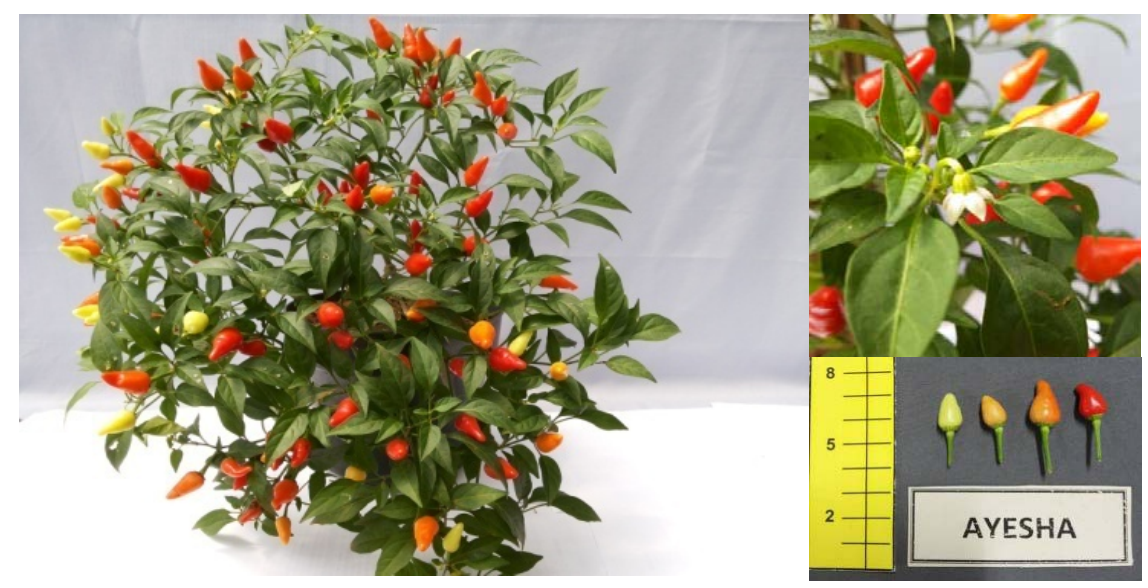

Gambar 2. Keragaan cabai hias varietas Ayesha 
Tabel 4. Deskripsi Varietas Cabai Hias Ayesha IPB

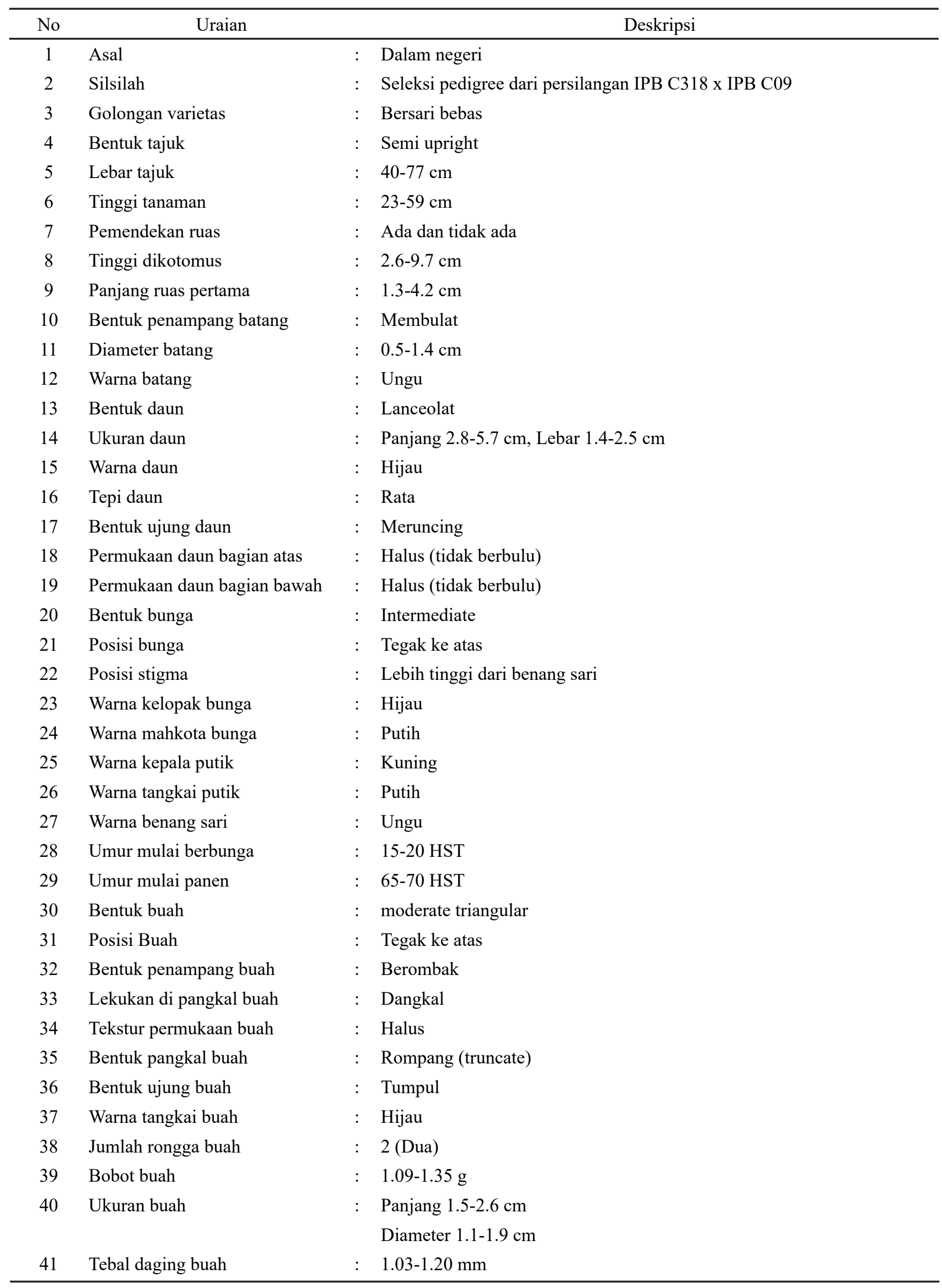


Tabel 4. Deskripsi Varietas Cabai Hias Ayesha IPB (Lanjutan)

\begin{tabular}{|c|c|c|}
\hline No & Uraian & Deskripsi \\
\hline 42 & Panjang tangkai buah & $1.5-2.4 \mathrm{~cm}$ \\
\hline 43 & Jumlah buah per tanaman & 48-127 buah \\
\hline 44 & Bobot per tanaman & $: \quad 65.27-101.17 \mathrm{~g}$ \\
\hline 45 & Warna buah muda & : Kuning \\
\hline 46 & Warna buah intermediat & : Oranye \\
\hline 47 & Warna buah matang & : Merah \\
\hline 48 & Rasa buah & : Pedas \\
\hline 49 & Bentuk biji & : Pipih \\
\hline 50 & Warna biji & : Kuning \\
\hline 51 & Bobot 1000 biji & $: \quad 3.72-3.73 \mathrm{~g}$ \\
\hline 52 & Populasi per hektar & : $\quad 16.000$ pot tanaman per hektar \\
\hline 53 & Kebutuhan benih per hektar & $: \quad 76-80 \mathrm{~g}$ \\
\hline 54 & Penciri utama & : 1. Bentuk buah membulat dengan ujung buah tumpul \\
\hline \multirow[t]{4}{*}{54} & Penciri utama & $\begin{array}{l}\text { 2. Terdapat beberapa warna buah dalam satu tanaman, warna buah muda } \\
\text { kuning (Yelow green group 145-C), warna buah intermediet oranye } \\
\text { (Orange group N25-B), warna buah matang oranye tua kemerahan (Or- } \\
\text { ange red N30-B) }\end{array}$ \\
\hline & Keunggulan varietas & : 1. umur berbunga pertama tergolong cepat (13-16 HST) \\
\hline & & 2. bentuk tanaman ideal (tinggi tanaman $25.218 \mathrm{~cm}$, lebar tajuk $46-53 \mathrm{~cm}$ ) \\
\hline & & $\begin{array}{l}\text { 3. keunikan organ bentuk ujung buah tumpul dan membulat (obtuse), } \\
\text { bentuk buah segitiga (triangular), bentuk pangkal buah rompang } \\
\text { (truncate), ada beberapa warna buah dalam satu tanaman, warna } \\
\text { buah muda kuning (Yelow green group 145-C), warna buah in- } \\
\text { termediet oranye (Orange group N25-B), warna buah matang oranye } \\
\text { tua kemerahan (Orange red N30-B), cocok sebagai tanaman hias }\end{array}$ \\
\hline 56 & Wilayah adaptasi & : Rumah kaca \\
\hline 57 & Pemulia & $\begin{array}{l}\text { Dr. Muhamad Syukur, Sobir, Awang Maharijaya, Syarifah Iis Aisyah, Dewi } \\
\text { Sukma, Sulassih, Arya Widura Ritonga, M. Ridha Alfarabi Istiqlal, Abdul } \\
\text { Hakim }\end{array}$ \\
\hline 58 & Peneliti & $\begin{array}{l}\text { : Darda Efendi, Ketty Suketi, Undang, Tiara Yudilastari, Ratih Lestari, Elsa } \\
\text { Tirta Wulandari, Bagas Akmala, Devi Alvida }\end{array}$ \\
\hline
\end{tabular}

\section{KESIMPULAN}

Varietas Ayesha IPB memiliki keunggulan sebagai berikut:

1. umur berbunga pertama cepat (13-16 HST) dan umur komersialisasi berupa tanaman di dalam pot mulai $65-$ $70 \mathrm{HST}$.

2. bentuk tanaman ideal dengan tinggi tanaman 25.218 $\mathrm{cm}$, lebar tajuk 46-53 $\mathrm{cm}$ dan bentuk tajuk kompak.

3. keunikan organ pada bentuk ujung buah tumpul dan membulat (obtuse), ada beberapa warna buah dalam satu tanaman, warna buah muda kuning (Yelow green 145-C), warna buah intermediet oranye (Orange N25-B), warna buah matang oranye tua kemerahan (Orange red N30-B) dan cocok untuk tanaman hias

\section{UCAPAN TERIMA KASIH}

Terima kasih disampaikan kepada kementerian Ristekdikti melalui berbagai penelitian sejak tahun 2016 sampai tahun 2017

\section{DAFTAR PUSTAKA}

Esin, A., B. Hilal, Y. Selcen, Y. Tolga. 2016. Androgenic responses of 64 ornamental pepper (Capsicum annuит L.) genotypes to shed-microspore culture in the autumn season .Turk J Biol 40: 706-717.

[IPGRI] International Plant Genetic Resources Institute. 1995. Descriptors for Capsicum (Capsicum spp.). 
International Plant Genetic Resources Institute. Roma. Italia.

Departemen Pertanian [Deptan]. 2011. Pedoman Penyusunan Deskripsi Varietas Hortikultura. Direktorat Perbenihan Hortikultura, Direktorat Jenderal Hortikultura, Kementrian Pertanian, Jakarta.

[Kementan] Kementrian Pertanian. 2006. Peraturan Menteri Pertanian Nomor : 01/Pert/SR.120/2/2006. Syarat Penamaan dan Tata Cara Pendaftaran Varietas Tanaman. Kementrian Pertanian. Jakarta. Indonesia.

Monteiro, C.E.S., T. Pereira, K.P. Campos. 2011. Reproductive characterization of interspecific hybrids among Capsicum species. Crop Breeding and Applied Biotechnology, 11: 241-249.

Naktuinbouw. 2010. Calibration books Capsicum annum L, sweet pepper, hot pepper, paprika, chili. Version 1. Naktuinbouw, Variety Testing Department. The ederlands. $86 \mathrm{pp}$.
Niu, G., P. Osuna, Y. Sun, D.S. Rodriguez. 2012. Seedling emergence, growth, and mineral nutrition of ornamental chile peppers irrigated with saline water. Hortscience 47(11):1653-1657.

Occhiuto, P.N., I.E. Peralta, P.D. Asprelli, C.R. Galmarini. 2014. Characterization of Capsicum germplasm collected in Northwestern Argentina based on morphological and quality traits. Agriscientia. Volume 31 (2): 63-73.

Rego, E.R., M.F. Nascimento, N.F.F. Ascimento, R.M.C. Santos, F.L.G. Fortunato, M.M. Rego. 2012. Testing methods for producing self-pollinated fruits in ornamental peppers. Horticultura Brasileira 30: 669672.

Sulassih, M. Syukur, Sobir, A. Maharijaya, A. Hakim, Ratih. 2017. Karakterisasi Lima Galur Cabai Hias dalam Rangka Pendaftaran Varietas Hasil Pemuliaan. Comm. Hort. J. Vol.1(1):26-33. 